\title{
O SERVIÇO SOCIAL NO CEPRE: \\ DA EXTENSÃO AO ENSINO E PESQUISA
}

Maria de Fátima de Campos Françozo ${ }^{1}$

\section{RESUMO}

O artigo apresenta as atividades do Serviço Social no Centro de Estudos e Pesquisas em Reabilitação “Prof. Dr. Gabriel Oliveira da Silva Porto” (CEPRE), unidade da Faculdade de Ciências Médicas da Unicamp. O CEPRE tem por finalidade a pesquisa, o ensino e a extensão na área da deficiência sensorial, contando para isso, com docentes de diferentes formações, em nível de graduação e de pós-graduação. O Serviço Social acompanha as finalidades do CEPRE, desenvolvendo sua prática interligada à pesquisa e ao ensino. Participando como componentes de diferentes equipes multidisciplinares, as assistentes sociais atuam com pessoas portadoras de deficiência visual ou de surdez e com suas famílias.

PALAVRAS CHAVES: Serviço Social; Reabilitação; Ensino; Pesquisa; Extensão.

A solicitação para que eu escrevesse sobre o Serviço Social no CEPRE foi uma oportunidade para refletir sobre os caminhos da profissão e do próprio CEPRE. O limite do tempo, no entanto, não permitiu um maior aprofundamento, seja da própria história do Serviço Social no CEPRE, seja sobre a prática que hoje lá acontece. Assim, o que será a seguir apresentado é uma exploração inicial do tema, uma primeira descrição do trabalho profissional do Serviço Social.

A prática de uma determinada profissão se faz ou é influenciada pelos condicionamentos externos - da estrutura econômica, política, por exemplo - mas é também fortemente influenciada pelo ambiente específico onde se desenvolve, isto é,

\footnotetext{
${ }^{1}$ Assistente Social, doutora em Saúde Mental pela UNICAMP, docente do CEPRE - Faculdade de Ciências Médicas, UNICAMP.
} 
pelo tipo de organização onde está inserida. Assim, para falar sobre o Serviço Social é preciso falar sobre o próprio CEPRE.

Em 1973 foi fundado o então Centro de Reabilitação Prof. Dr. Gabriel Porto, como uma unidade da Faculdade de Ciências Médicas da Unicamp, com a finalidade de atender pessoas com surdez ou com deficiência visual (FERREIRA, 2000). Profissionais de diferentes áreas foram contratados para realizar o atendimento de reabilitação e, entre eles, assistentes sociais. Consoante aos propósitos do Centro, a assistente social realizava seu trabalho diretamente com a pessoa portadora de deficiência e/ou com seus familiares, desenvolvendo atividades como plantão e triagem dos casos, orientação, encaminhamentos e o trabalho de grupos. Nesse período, também, o planejamento e o aconselhamento genético eram práticas que a assistente social desenvolvia em conjunto com outros profissionais da equipe técnica.

É importante lembrar que a profissão no Brasil, nesse período, era marcadamente dividida, nas discussões teóricas e nas ações, em 'caso', 'grupo' e ‘comunidade’ e, portanto, o trabalho no Centro não fugia a essa determinação. A busca da cientificidade (uma preocupação importante na época) através da elaboração de adequada documentação do trabalho realizado em suas diferentes etapas, por exemplo, também estava presente entre as preocupações da categoria no Centro.

A década de 80 traz uma ampla divulgação e implementação das idéias e propostas do Serviço Social Reconceituado. No Centro, o trabalho das assistentes sociais buscava, além das atividades tradicionais, o envolvimento dos pais na luta pelos direitos dos surdos e nos encaminhamentos dessa luta. A criação, pelos pais, da APASCAMP (Associação de Pais e Amigos dos Surdos de Campinas) ${ }^{2}$ é um exemplo. A realização de convênio para obtenção de verbas que subsidiassem a participação dos

\footnotetext{
${ }^{2}$ Ver SANNT’ANNa, 1995.
} 
sujeitos no processo de reabilitação pode ser identificado como um outro esforço de então.

Em 1993 cria-se oficialmente o CEPRE - Centro de Estudos e Pesquisas em Reabilitação "Prof. Dr. Gabriel O. da Silva Porto”. Mudanças não só administrativas, mas principalmente de finalidades acontecem de maneira a aproximar o Centro, em termos de seus objetivos e atividades, às finalidades e características da universidade. Como o próprio nome indica, o Centro torna-se local de atendimento, de ensino e de pesquisa na área da deficiência sensorial. Obviamente, as mudanças não acontecem de maneira isolada e abruptamente. São decorrências de um movimento do conjunto de seus profissionais que começavam a buscar formação em pesquisa através de cursos de pós-graduação. Além disso, em função de demanda externa, o Centro tornava-se campo de estágio para estagiários de diferentes cursos de graduação bem como passava a realizar cursos de extensão.

O Serviço Social participou ativamente desse processo. Hoje, faz parte de seu cotidiano, o desenvolvimento de atividades de extensão, de ensino e de pesquisa, que serão, a seguir, apresentadas.

\section{EXTENSÃO}

As atividades de extensão, no CEPRE, estão agrupadas em Programas e voltamse para o atendimento, por faixas etárias e nível de desenvolvimento, de grupos específicos de usuários, pessoas com deficiência visual ou com surdez. Em decorrência dessas características, agrupam-se os profissionais das diferentes áreas de intervenção. O Serviço Social está presente nos diferentes programas:

- Programa de orientação às famílias de crianças surdas. 
O Programa volta-se para orientação de famílias de crianças surdas nos aspectos relativos à surdez: lingüístico, cognitivo, educacional, afetivo e social. Os diferentes profissionais (Fonoaudióloga, Psicóloga, Assistente Social, Pedagoga, Instrutor de Línguas de Sinais) realizam atendimentos de orientação e terapêutico, individual ou em grupo.

A característica fundamental do Programa é trabalhar com as possibilidades comunicativas da criança surda através da língua de sinais e da língua oral. As famílias são orientadas quanto aos direitos do surdo na Legislação Brasileira e são encaminhadas para os recursos sociais, quando necessário.

- Linguagem e Surdez: Programa Infantil

O trabalho educacional é a característica principal do Programa, favorecendo a construção do processo de aquisição e desenvolvimento da linguagem oral, leituraescrita e raciocínio lógico-matemático, como preparação para a escolaridade. Tem como objetivo propiciar um contexto lingüístico para o uso efetivo da Língua Brasileira de Sinais com a participação de um instrutor surdo fluente nesta língua. São profissionais neste Programa: Assistente Social, Pedagoga, Lingüista, Arte Educadora, Professor de Língua de Sinais, e Fonoaudióloga. O trabalho de orientação familiar ocorre com o trabalho dos profissionais de Serviço Social, Pedagogia e Fonoaudiologia.

- Programa Escolaridade e Surdez

O Programa tem dois grandes objetivos: o primeiro é atender o surdo que freqüenta escolas da rede de ensino regular no ensino fundamental em sua vida escolar, dando ênfase à aquisição e desenvolvimento da leitura e da escrita, do pensamento lógico-matemático e a construção e/ ou desenvolvimento da Língua Brasileira de Sinais. O segundo objetivo é propiciar o início do processo de escolaridade ao adolescente e adulto surdo que não freqüentaram escolas anteriormente, introduzindo-o à Língua 
Brasileira de Sinais e à escrita do português e, por meio delas, ao conhecimento de outras áreas como matematica, ciências e estudos sociais. Assistente Social, Fonoaudióloga, Lingüista, Pedagoga, Psicóloga e Instrutor de Língua de Sinais atuam no Programa.

- Programa Infantil na Deficiência Visual.

Tem como objetivo intervir na facilitação dos diversos aspectos do desenvolvimento neuropsicomotor, favorecendo o uso funcional da visão, a integração dos sentidos remanescentes e a prevenção de deficiências secundárias. Aborda aspectos educacionais, preparando a criança para o ingresso na vida escolar. Por meio de equipe constituída por Assistente Social, Psicóloga, Pedagogas, Professora Especializada, Fisioterapeuta, Fonoaudióloga e Terapeuta Ocupacional, oferece atendimentos individuais e grupais à crianças com baixa visão ou cegueira e suas famílias.

- Programa de Adolescentes e Adultos com Deficiência Visual.

O Programa tem como objetivo instrumentalizar a pessoa deficiente visual, com baixa visão ou cegueira, para que alcance o maior nível de autonomia e independência no seu cotidiano. Realiza atendimentos individuais e grupais por meio de uma equipe interdisciplinar composta por Assistente Social, Terapeuta Ocupacional, Pedagoga, Professora Especializada e Fisioterapeuta. Junto aos usuários, a equipe desenvolve atividades de reabilitação tais como: leitura e escrita Braile, adaptação a auxílios ópticos, orientação e mobilidade, orientação e readaptação profissional e atividades da vida diária. Oferece ainda recursos de informática com software sonoro Dos Vox, Lente Pró e Virtual Vision, além de impressoras em Braile e comum.

- GIADI - Grupo Interdisciplinar de Avaliação do Desenvolvimento Infantil 
O CEPRE, em conjunto com o Departamento de Neurologia da F.C.M. criou o GIADI - Grupo Interdisciplinar de Avaliação do Desenvolvimento Infantil, coordenado por uma neurologista infantil e composto por fisioterapeuta, psicóloga, fonoaudióloga, terapeuta ocupacional e assistente social, em colaboração interdisciplinar. Têm desenvolvido pesquisas com bebês de baixo peso e normais, acompanhando-os, mensalmente, no primeiro ano de vida. As várias pesquisas resultantes do trabalho do GIADI enfocam diferentes aspectos do desenvolvimento do bebê: neurológico, visual, motor, afetivo, de audição e linguagem. buscando detectar, o mais precocemente, alterações do desenvolvimento para encaminhamento aos recursos de habilitação. A finalidade do conjunto de pesquisas do GIADI, portanto, é a de oferecer para a sociedade um sistema de detecção da anormalidade no primeiro ano de vida da criança e a formulação de um programa de intervenção.

No contexto dos Programas, o Serviço Social desenvolve atividades comuns nas diferentes etapas do processo de habilitação e reabilitação:

- Plantão / triagem / primeiros atendimentos

Neste tipo de atividade são realizadas entrevistas para a inscrição dos usuários em um dos programas. Um conjunto de informações é levantado, buscando-se conhecer o perfil sócio-econômico e familiar, assim como informações são veiculadas, no sentido de esclarecer a pessoa que procura o CEPRE sobre os serviços que são ali oferecidos, o funcionamento dos programas, os recursos que conta para participação e outros aspectos que surgem na dinâmica das entrevistas, aspectos específicos à deficiência, ao processo de habilitação e reabilitação, ou a outras situações de vida da pessoa .

- Continuidade dos Atendimentos

Uma vez que o usuário ingressou em um dos programas, o trabalho dos diferentes profissionais acontece de maneira sistemática (em geral, com atendimentos 
semanais, variando de uma a três vezes por semana), contínua, por períodos que variam de alguns meses a anos, dependendo da faixa etária e tipo de deficiência. O Serviço Social mantém seus atendimentos, algumas vezes individualmente, outras em grupo, dependendo dos objetivos do Programa em que está inserido e das demandas do usuário.

Nesse processo de atendimentos, muitas vezes, diferentes encaminhamentos são realizados, especialmente para outros serviços da área da saúde da própria Universidade, para realização de exames e complementação de diagnósticos. Contatos com outras instituições são necessários com grande freqüência, em especial com as escolas que crianças e adolescentes usuários do CEPRE freqüentam no sentido de esclarecer e informar sobre questões ligadas à deficiência visual ou à surdez - direitos, características, especificidades. Pode-se dizer que se estabelece uma 'rede’ de contatos e informações entre a assistente social e os vários outros profissionais inseridos nos diferentes serviços e recursos.

Também são realizados atendimentos em grupos, tendo em vista trabalhar as necessidades sociais comuns dos usuários e a reflexão sobre temas como inclusão/exclusão social, reabilitação e saúde no contexto institucional e social. Ainda, nessa modalidade de atendimento, realiza-se junto aos usuários e familiares orientação social sobre recursos da comunidade, políticas e legislação sociais e direitos de cidadania referentes à pessoa com deficiência. Tais grupos podem contar com a participação de outros profissionais da equipe ou de outros serviços da universidade, dependendo do assunto a ser trabalhado.

Grupos de convivência são realizados com mães, com pais e ou com outros familiares para troca de experiências e de vivências em relação à deficiência e ao processo de reabilitação. 
O atendimento familiar, em que se trabalha com o casal e/ou com a família do usuário se constitui em outra modalidade de atendimento.

De maneira esporádica ou complementar a estas atividades aqui sinteticamente descritas, outras são desenvolvidas. Algumas são respostas pontuais a determinadas questões identificadas no cotidiano institucional, outras surgem como necessidades transitórias ou ainda, como experiências para futuros projetos. Exemplos dessas situações são: Projeto Sala de Espera, Boletim para Famílias, Grupo de Pais (dirigido ao pai da criança, especificamente), Grupo de Irmãos.

Por fim, é importante mencionar como característica do trabalho no CEPRE, o trabalho em equipe, algumas de natureza multidisciplinar outras de natureza interdisciplinar $^{3}$. O Serviço Social tem um papel, muitas vezes, de mediador de informações e conhecimentos sobre as famílias, sobre a realidade vivida dos usuários que vem esclarecer, vem informar o trabalho de outros profissionais da equipe. O manejo de uma técnica, a realização de um exercício que deve ser feito por alguém da família com a criança surda ou com deficiência visual, por exemplo, podem se melhor adequados quando há informações sobre o cotidiano, o modo de vida daquela família. Para isso, é fundamental aos profissionais da equipe, o conhecimento que a assistente social tem sobre o usuário, sua família e suas condições de vida.

\section{ENSINO}

O Serviço Social desenvolve atividades de ensino através de aulas em cursos de graduação, especialização, de extensão e de aprimoramento; também oferece estágio para alunas de graduação em Serviço Social. Alguns desses cursos são específicos ao Serviço Social (aprimoramento e extensão), outros não. Os cursos de especialização, por

\footnotetext{
${ }^{3}$ A questão da interdisciplinaridade mereceria uma reflexão a parte, por isso optamos apenas por pontuar as diferentes naturezas do trabalho em equipe.
} 
exemplo, são destinados a profissionais de diferentes formações e que estejam atuando em áreas relacionadas à deficiência e reabilitação. Neles, as disciplinas relativas às políticas sociais, direitos e cidadania e aos estudos de família são de responsabilidade do Serviço Social. Na graduação, no curso de fonoaudiologia, assistentes sociais ministram disciplinas com estas mesmas características. Pode-se dizer que este tipo de atividade é bastante interessante, na medida em que há um dialogo do Serviço Social com outras profissões que trabalham com o humano e com o social.

\section{PESQUISA}

As pesquisas desenvolvidas pelos profissionais do CEPRE estão agrupadas em três grandes linhas:

- Avaliação e Prevenção de Deficiências - em que se busca o desenvolvimento de instrumentos que possibilitem a avaliação e prevenção de deficiências visuais e surdez em seus diferentes aspectos.

- Desenvolvimento Humano: Surdez e Deficiência Visual - em que se busca analisar o processo de desenvolvimento de crianças e adolescentes com deficiência visual ou surdez em seus diferentes aspectos.

- Família, Comunidade e Diferença - investiga aspectos da relação de deficientes visuais e surdos na família e na comunidade, incluindo o desenvolvimento de metodologias de ação.

Assim, são algumas das pesquisas em desenvolvimento pelo Serviço Social (seja desenvolvida por um profissional ou em conjunto com outros profissionais da equipe):

1. Reconhecimento de necessidades específicas e inclusão social: as demandas identitárias no campo dos direitos à igualdade e à diferença. 
2. Caracterização do perfil dos pacientes encaminhados para a clínica de Fonoaudiologia da FCM/Unicamp (em conjunto com outros profissionais).

3. Adesão e expectativas de pais em relação a um Programa de Avaliação do Neurodesenvolvimento de Lactentes.

4. Reações parentais à suspeita de surdez de recém-nascidos.

5. A discussão dos arranjos familiares no desenvolvimento da criança deficiente visual.

Como indicado nos próprios títulos, as pesquisas acompanham, ou melhor, estão interconectadas às atividades assistenciais. Acontecem de maneira concomitante e seus resultados sustentam mudanças em práticas não só da assistente social como da equipe ou, outras vezes, nas diretrizes e políticas institucionais.

A estreita vinculação das atividades de extensão, pesquisa e ensino são o que, hoje, caracteriza o Serviço Social no CEPRE.

\begin{abstract}
This paper describes the role Social Work plays at CEPRE - Centro de Estudos e Pesquisas em Reabilitação - Medical School at the Universidade Estadual de Campinas (UNICAMP). CEPRE is a Center for teaching, research and community services in the areas of deafness, blindness and low vision. Its staff comprises a range of professionals from different fields of specialty. Social Work's practice is connected to teaching and research. As part of multidisciplinary teams, social workers deal, mainly, with deaf or visually impaired persons and their families.
\end{abstract}

KEYWORDS: Social work; Rehabilitation; Teaching; Research; Services. 


\section{REFERÊNCIAS BIBLIOGRÁFICAS}

FERREIRA, H. O Centro - ontem e hoje. Campinas, ago 2000. Material apostilado.

SANT’ANNA, I. A. Z. A atuação do Serviço Social na fundação e organização de uma Associação de Pais e Amigos de Surdos, Cadernos de Serviço Social, Campinas:

PUCCAMP, n. 6, p. 15-7, 1995. 
